\title{
Economics of robots and automation in field crop production
}

\author{
James Lowenberg-DeBoer ${ }^{2}$. Iona Yuelu Huang' ${ }^{1}$ . Vasileios Grigoriadis ${ }^{2}$. \\ Simon Blackmore ${ }^{2}$
}

Published online: 17 May 2019

(C) The Author(s) 2019

\begin{abstract}
This study reviewed research published after 1990 on the economics of agricultural mechatronic automation and robotics, and identified research gaps. A systematic search was conducted from the following databases: ScienceDirect, Business Source Complete, Wiley, Emerald, CAB Abstract, Greenfile, Food Science Source and AgEcon Search. This identified 4817 documents. The screening of abstracts narrowed the range to a dataset of 119 full text documents. After eligibility assessment, 18 studies were subjected to a qualitative analysis, with ten focused on automation of specific horticultural operations and eight related to autonomous agricultural equipment. All of the studies found some scenarios in which automation and robotic technologies were profitable. Most studies employed partial budgeting considering only costs and revenues directly changed by the introduction of automation or robotics and assuming everything else constant. None examined cropping system changes, or regional and national impacts on markets, trade and labour demand. The review identified a need for in-depth research on the economic implications of the technology. Most of the studies reviewed estimated economic implications assuming that technology design parameters were achieved and/or based on data from prototypes. Data are needed on the benefits and problems with using automation and robotics on farm. All of the studies reviewed were in the context of agriculture in developed countries, but many of the world's most pressing agricultural problems are in the developing world. Economic and social research is needed to understand those developing country problems, and guide the engineers and scientists creating automation and robotic solutions.
\end{abstract}

Keywords Robot $\cdot$ Automation $\cdot$ Economics $\cdot$ Profit $\cdot$ Crop production $\cdot$ Farm labour

Electronic supplementary material The online version of this article (https://doi.org/10.1007/s1111 9-019-09667-5) contains supplementary material, which is available to authorized users.

Iona Yuelu Huang

ihuang@harper-adams.ac.uk

1 Department of Land, Farm \& Agribusiness Management, Harper Adams University, Newport, Shropshire TF10 8NB, UK

2 Harper Adams University, Newport, UK 


\section{Introduction}

The rapid growth of agricultural crop robotics in the last decade results from, (a) the convergence of maturing mechatronics technology, making such automation technically feasible and, (b) the demand for alternatives to human labour in crop production. Worldwide, agricultural workers are difficult to hire and retain. Increasing environmental and food safety concerns push agriculture to manage and apply inputs more precisely (Finger et al. 2019). The engineering side of agricultural robotics has advanced rapidly (Duckett et al. 2018; Shamshiri et al. 2018), but understanding of the economic implications has lagged. The objective of this study is to review the publicly available research on the economics of crop robotics and identify research needs and gaps. The results of this study will be of interest to agricultural researchers, agribusinesses, farmers and agricultural policy makers.

The definition of "robot" is debated (e.g. Robot Institute of America-RIA undated; Simon 2017). The etymology of "robot" is the Czech word for serf, worker or servant. The official RIA definition is: "a reprogrammable, multifunctional manipulator designed to move material, parts, tools, or specialized devices through various programmed functions for the performance of a variety of tasks". Some of the disagreements about the definition of robotics are about need for mobility, degree of autonomy (can function without direct human intervention), ability to learn, range of decision making and extent of pre-programmability.

The characteristics of agricultural robots have been described by several authors (e.g. Duckett et al. 2018; Blackmore 2007), but there is no widely agreed definition. Because the focus of this study is on the economics of robotics for crop production in open fields, the working definition of a "field crop robot" for this study was: a mobile, autonomous, decision making, mechatronic device that accomplishes crop production tasks (e.g. soil preparation, seeding, transplanting, weeding, pest control and harvesting) under human supervision, but without direct human labour. Mobility is an essential part of the definition because field crops are typically geographically dispersed in the landscape. Autonomy is also essential because the field environment is not entirely controllable. Among the decisions that a field crop robot might make are distinguishing a crop plant from a weed, identifying an insect to choose the appropriate pesticide for micro dosing, choosing ripe fruits or vegetables, and stopping when it encounters an unknown obstacle.

Of course, there are many types of robotics and decisions had to be made about the kind of studies and articles to be included. The review includes papers on the economics of partially roboticized field crop operations, especially those in which the agricultural work (e.g. seeding, harvesting and weeding) has been automated, but the equipment is still guided through the field by a human driver. These studies provide useful examples of economic analysis of automated agricultural systems and it is assumed that when the economic and social conditions require it, they could be made autonomous relatively easily. The review includes both broad acre and horticultural crops grown in open fields, but does not include studies and articles on livestock or protected environment production even though both are areas in which the use of robotics has advanced more rapidly than in field crop production. Intensive livestock farming and greenhouse production operate in more controlled environments than field crops and consequently, robots have been developed more quickly than for crops grown in open fields. For example, in 2015, roughly one quarter of the dairy farms in Denmark and the Netherlands used robotic milking (Dairy Global 2015). Robotics for intensive livestock and greenhouses are substantially different from those needed for field crops. They can often be stationary 
(e.g. milking robots) or with limited mobility (e.g. greenhouse robots on rails). Because intensive livestock and greenhouse systems are more controllable, the need for autonomy and decision making is less. The review also excludes the numerous studies on the economics of Global Navigation Satellite Systems (GNSS) for agriculture because they all assume that a human driver is in direct control of the equipment. However, it must be noted that agricultural GNSS has helped lay the basis for autonomous agricultural equipment.

Economic analysis of new technology in agriculture is important for at least two reasons: "(1) guiding future research and (2) informing farmer and agribusiness adoption decisions. Because profitable technologies are more likely to be widely adopted and the environmental and social benefits of the technologies are more likely to be realized when they are widely adopted, those who fund research and desire impact are often guided by the potential economic feasibility. With a similar motivation, researchers use potential economic benefits as an important factor in deciding how to allocate their time. In research planning, even a negative economic estimate for a technology is valuable, especially if key economic constraints can be identified and research targeted to resolve those constraints. Before investing in a new technology, farmers and agribusiness people often seek out economic research studies. They realise that such studies seldom replicate completely their on-farm or business situations, but they can identify key barriers to profitable use of the technology and characteristics of businesses that could use them economically.

In precision agriculture, economic estimates have played a key role in guiding research and adoption decisions (Lowenberg-DeBoer 2018). The currently observed precision agriculture adoption patterns were accurately predicted by economic studies done in the $1990 \mathrm{~s}$ and in the early years of the 21 st Century. Those studies that looked beyond partial budgeting to include changes in management costs, training expense and personnel-related issues were particularly useful. Since GNSS guidance was introduced for ground-based agricultural equipment in the late $1990 \mathrm{~s}$, almost all economic studies have estimated economic benefits and substantial qualitative advantages, which were more difficult to measure. Consequently, the rapid adoption of this and related technologies should not come as a surprise. Since the early $1990 \mathrm{~s}$, variable rate fertilizer studies have shown mixed economic outcomes and the adoption record reflects that mixed picture with substantial adoption in some niche situations, but with widespread adoption waiting for technical breakthroughs that reduce costs and enhance effectiveness. Economic analysis of crop robotics could play a similar role in the research planning and adoption of the technology.

The general objective of this study was to provide a synthesis of the results of research on the economics of field crop robotics. The specific objectives were to: (1) list and summarise the publicly available research on the economics of field crop robotics, (2) identify research gaps and needs related to crop robotics and (3) propose research topics that need urgent attention. This review contributes to science by summarizing the knowledge that has been accumulated about the economics of crop robots, suggesting mechanisms for how those facts fit together, and identifying gaps in the science. The primary focus of this study is on farm level profitability because without profitability crop robots will not be widely used and the expected environmental, social and food safety benefits will not be achieved. Environmental, social and food safety benefits of the potentially profitable autonomous crop technologies were noted when identified. The overall hypothesis is that most studies of the economics of field crop robotics use partial budgeting to focus on changes in variable cost and consequently there is an urgent need for a more systematic study of the potential impact of automation and robotics. 


\section{Materials and methods}

A systematic literature review identified published research on the economics of crop production robots and automation. The Preferred Reporting Items for Systematic Reviews and Meta-Analysis (PRISMA) (Moher et al. 2009) approach was followed for reporting the searches, screening and synthesis.

The searches were restricted to those published in English and between January 1990 and May 2018. The decision to exclude articles before 1990 was made because there was almost no economic research on mechatronic automation or autonomous field robots before that time. However, it is important to recognise that this review was not exhaustive. It was limited to the databases that the team was able to access.

Databases used for this search included AgEcon Search, EbscoHost (including Business Source Complete, CAB Abstract, Greenfile, Food Science Source), Emerald, ScienceDirect and Wiley Online. The search string was adapted to the syntax of each database. Boolean operators (AND, OR) and wildcards (*) were used where accepted by the database/search. Table 1 shows the search field and search string used for each database.

The search string was composed of three components which were combined with AND:

(1) Economic analysis-economic* OR profit* OR financ* OR cost* (It was believed that this would include the key types of economic evaluation such as cost analysis, cost-benefit analysis, cost-effectiveness analysis etc.)

AND

(2) Robotics-robot* OR automatic OR automated OR automation

AND

3) Agricultural sector (open field crops) —agri* OR field OR crop* OR plant* OR harvest* OR seed* OR fruit* OR apple* OR asparagus* OR barley OR banana* OR beetroot* OR blueber* OR broccoli OR carrot* OR cauliflower* OR cabbage* OR celer* OR cereal OR cherr* OR citrus* OR corn OR cotton* OR cucumber* OR eggplant* OR garlic OR grape* OR herbaceous OR lemon* OR lettuce* OR maize OR olive* OR onion* OR orange* OR orchard* OR pepper* OR potato* OR raspber* OR strawber* OR sugar* OR tomato* OR radicchio OR scallion* OR soy*bean* OR vineyard* OR weed OR wheat

This search string was used for all databases apart from AgEcon Search. It was believed that AgEcon Search contains articles all related to agriculture. Therefore, it was deemed unnecessary to add the component representing agriculture sector.

The search terms were pilot tested and agreed upon within the research team. This search generated 5094 articles. After removing duplicates, 4792 articles remained. In addition to the search, 25 more articles were identified from conference proceedings and the bibliography of the seminal articles. This led to the final 4817 titles for initial screening.

Screening was conducted with the EPPI-Reviewer 4. EPPI is an acronym that originally stood for "Evidence of Policy and Practice Information" (Thomas et al. 2010). Two of the co-authors screened the titles and abstracts with sample double screening (40\%). Discrepancies were resolved through discussion with each other and checking with the third and 


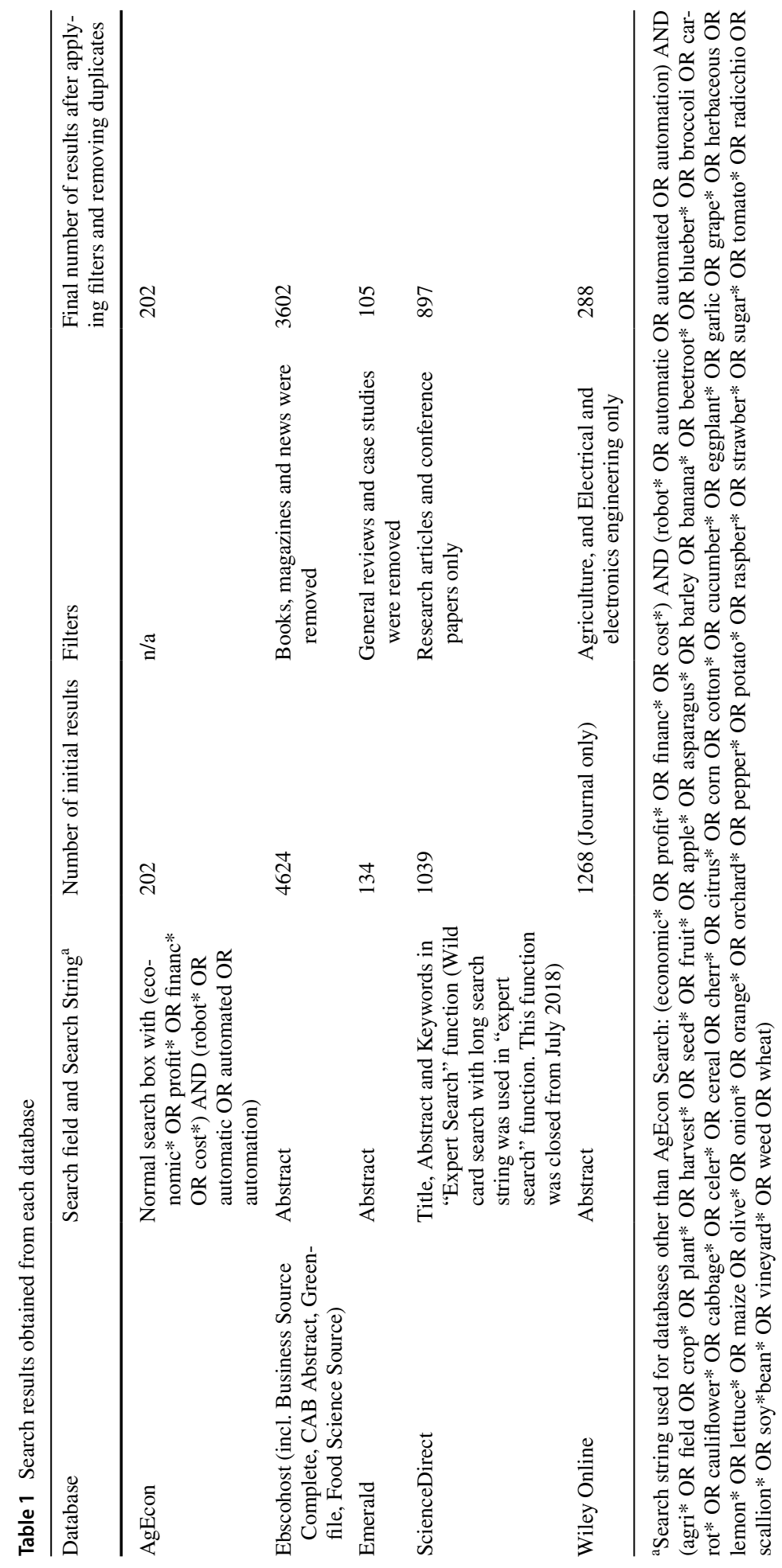


fourth co-authors. A similar approach was taken for full-text screening. Inclusion criteria were discussed and agreed by the full research team. It was decided that only articles which reported original research in agricultural mechatronic automation and robotics for the production of the crops in the following list and contained some element of economic analysis would be included for full-text synthesis analysis.

The following crops were explicitly included:

- Viticulture-grape

- Field crops - asparagus, broccoli, beets, carrots, celery, cabbage, cauliflower, cereal crops, cotton, cucumber, lettuce, eggplant, onion, scallions, garlic, maize (corn), soybean, barley, wheat, sugar beet, sugarcane, sweetcorn, tomato, pepper, potato

- Soft fruits - strawberry, blueberry, raspberry

- Top fruits-apples, pears, citrus, orange, lemon olive, cherry, plums

As noted in the introduction, greenhouse crops were excluded because both the technology and the economics are substantially different from those of field crops. Articles focused on conventional mechanization were also excluded, but those involving mechatronic automation were retained even if the technology was not full autonomous.

Screening on title and abstract was based on whether the original research was on robotics or automation for at least one of the above mentioned crops. Articles with an obvious lack of economic analysis were also excluded. However, extreme caution was exercised. This means that, if in any doubt, the titles would be included for full text review. This was to minimise the chance of missing any relevant articles. Through this screening procedure, 119 titles were retained for full-text screening.

Full text assessment of eligibility was based on whether some type of economic analysis was conducted. This ranged from basic cost description or cost analysis to more complete cost-benefit analyses.

The complete procedure of literature identification, screening and final inclusion and exclusion process is presented in Fig. 1.

Out of the 119 articles, four were found to be multiple publications on same studies (Cembali et al. 2008; Mazzetto and Calcante 2011; Pedersen et al. 2006; 2008). 97 articles were excluded for the following reasons:

- No economics $(\mathrm{n}=44)$

- Not robotics $(\mathrm{n}=16)$

- Not original study $(\mathrm{n}=27)$

- Not open fields $(\mathrm{n}=10)$

This led to the remaining 18 articles on which this qualitative analysis is based. Statistical meta-analysis (Borenstein et al. 2009) was not attempted because of the diversity of methodologies used in the crop robotic economics studies found. 


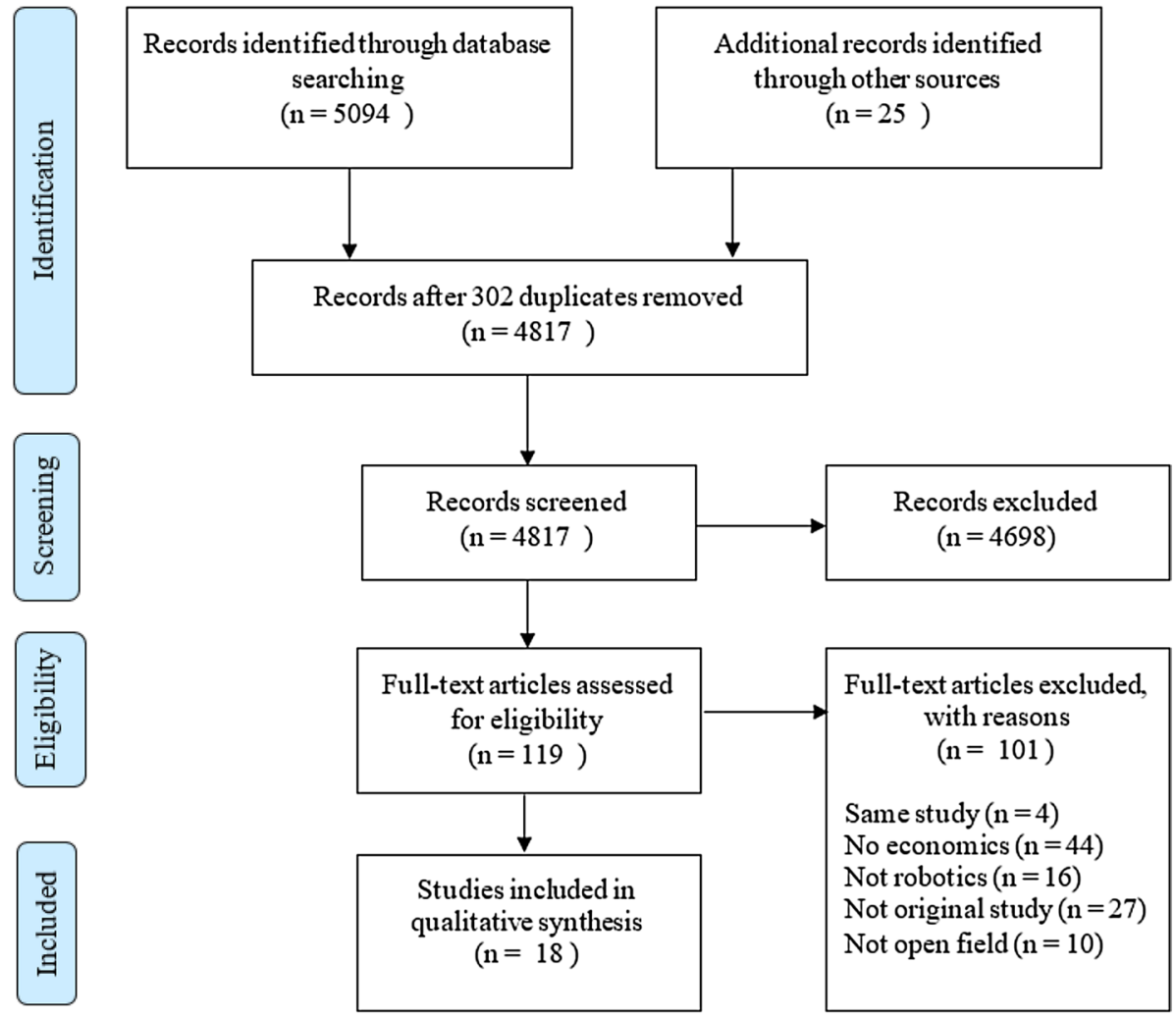

Fig. 1 Process of literature search and screening (PRISM flow diagram)

\section{Results}

\section{Characteristics of the full-text studies analysed}

Of the 18 studies which included economic analysis of automation/robotics, ten came from the USA, four from Denmark (Table 2). The other countries among the 18 papers with economics were United Kingdom, Greece, Italy, Israel, Japan and Germany. Two of the studies from the US were based on international collaboration. One of these was part of a Danish study which involved multiple countries.

Concerning the type of automation/robotic technology studied, harvesting $(n=5)$ and weeding $(n=4)$ were the top two types of automation/robotics for which economics was studied. Other automation/robotics included in the 18 documents were for scouting, planting, transplanting, seeding and pruning.

Of the 18 included in the full-text review, crops studied were sugar beet $(n=4)$, asparagus $(n=4)$, grapes $(n=2)$, lettuce $(n=2)$, and apple, celery, cabbage, radicchio, carrots, sugarcane, olive, tomato and melon $(n=1$ for each). Most studies reviewed focused on one or two crops, but two of the studies were whole farm (i.e. Sørensen et al. 2005; Shockley and Dillon 2018). 


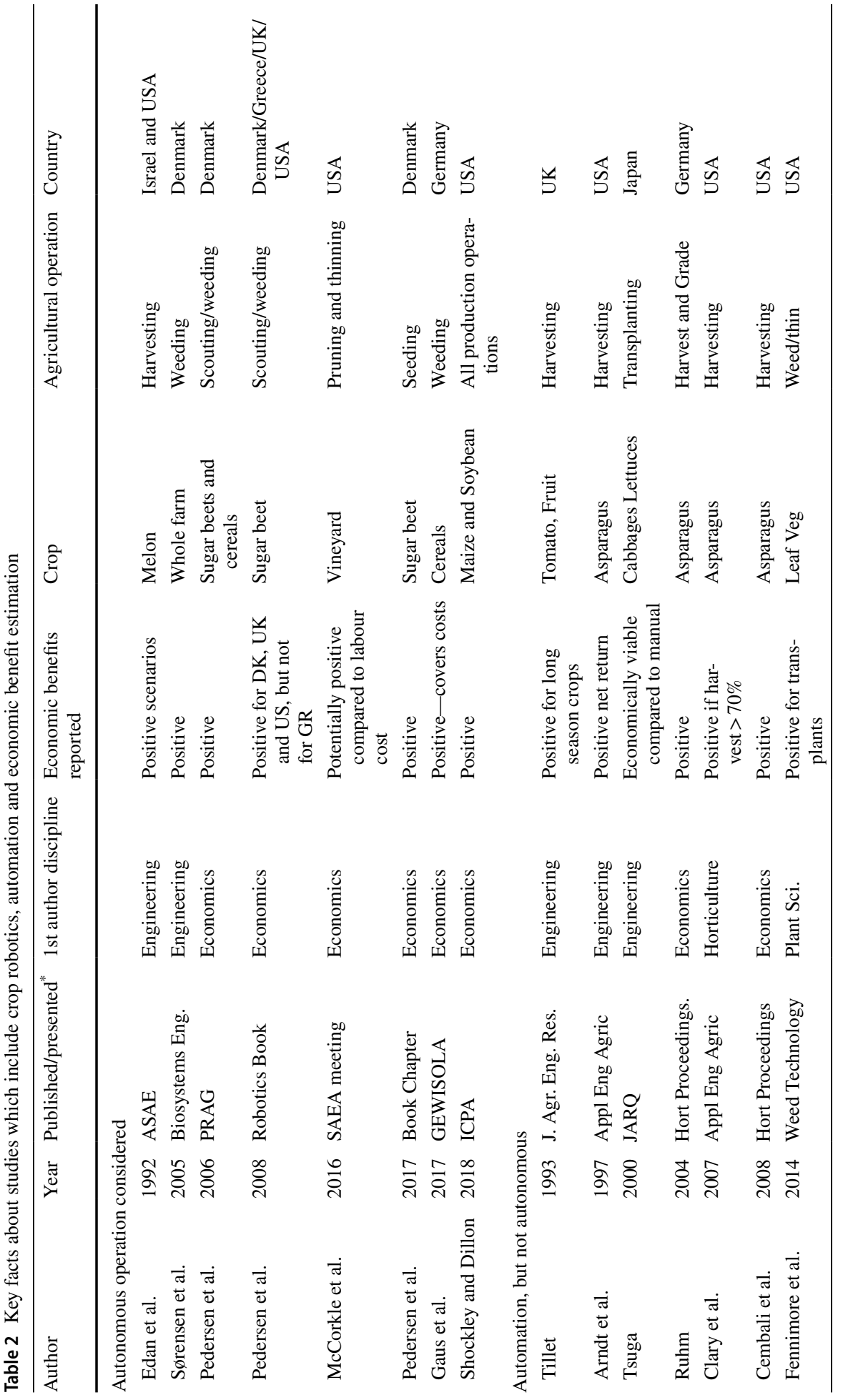




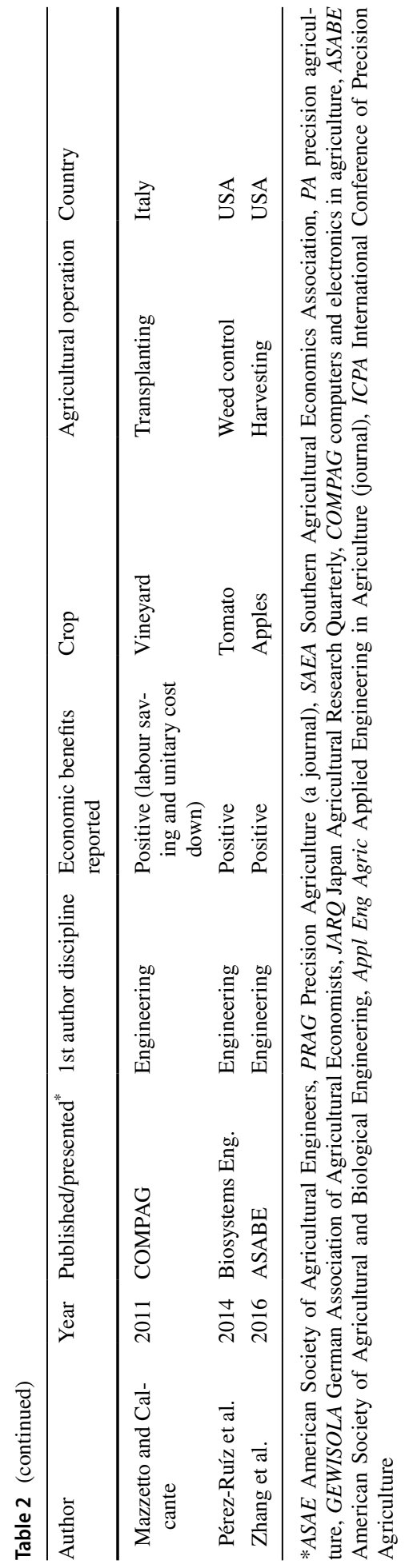




\section{Economic benefits of robotic technology}

In total, the literature screening produced 18 studies published between 1990 and 2018 in which some form of economic analysis was conducted for robotics and mechatronic automation of field crops. Because of the different methodologies used in the 18 studies, this analysis focused on qualitative rather than quantitative synthesis. It aimed to identify the economic benefit or viability assessed, the methods used in the assessment (Tables 2 and 3), and aspects of automation and robotics that have not yet been studied. All 18 of the studies identified some scenarios in which automation or robotics would be profitable.

\section{Autonomous operations considered}

Of the eight studies which reported some economic analysis of autonomous agricultural robotics, five used partial budgets and three used methodologies that provided a somewhat broader perspective. Sørensen et al. (2005) used scenario planning to assess the potential for robotic weeding of organic crops. Scenario planning is whole farm budgeting drawing on input from farmers, researchers and farm advisors to specify the parameters. They created eight organic farm scenarios, but most of the analysis focused on the scenario involving sugar beet and carrot production because of the labour involved in organic production. With manual weeding, sugar beet and carrot production was expected to add over $100 \mathrm{~h} /$ ha of labour. If a two-row $(1.0 \mathrm{~m})$ robotic weeder required an investment of $€ 26,882$ and was $80 \%$ efficient, weeding costs for the 5 ha of sugar beet and carrot would be reduced by about $50 \%$. They found that a farmer could pay up to $€ 40,000$ for the robotic weeder and still be better off than with manual weeding. Contract weeding may reduce costs even more because it would allow the robot to cover a larger area each crop season.

McCorkle et al. (2016) employed a relatively detailed financial simulation model of a vineyard enterprise, but only treated robotics in a sensitivity test, as a potential substitute for labour. They estimated that a 20.2 ha vineyard would require $334.7 \mathrm{~h} / \mathrm{ha}$ at a cost of US $\$ 4,402.58 / \mathrm{ha}$, and a 40.4 ha vineyard would require $282.8 \mathrm{~h} / \mathrm{ha}$ at a cost of US $\$ 3,799.33$ / ha. They emphasized the cost savings if human workers were replaced with robots. Their methodology facilitated analysis of risk, but lacked detail on how robotics might affect variability.

Edan et al. (1992) used partial budgets to assess the potential for automation of melon harvest, but consider autonomy as a sensitivity test. Their treatment of autonomy was very limited because GNSS guidance technology was not available for agricultural equipment when the study was done in 1992. Edan et al. (1992) reported results in terms of the breakeven area for an initial investment ranging from US\$50,000 to US\$250,000, and manual harvest costing US\$247/ha to US\$741/ha. Over that initial investment range, the autonomous melon harvester was shown to be economically competitive for 202.4 ha of melon when manual harvesting cost was less than US\$494/ha. If the initial investment is US $\$ 50,000$, the breakeven melon area drops to less than 81 ha over the range of manual labour costs considered. For a low manual labour cost of US\$247/ha and initial equipment cost of greater than US\$50,000, the breakeven area is between 202.4 and 404.8 ha It should be noted that among the 18 studies reviewed in detail, Edan et al. (1992) provided the most detailed explanation of their cost estimate, including a detailed parts list for the automated melon harvester, construction cost estimate including manufacturer profit margin, 


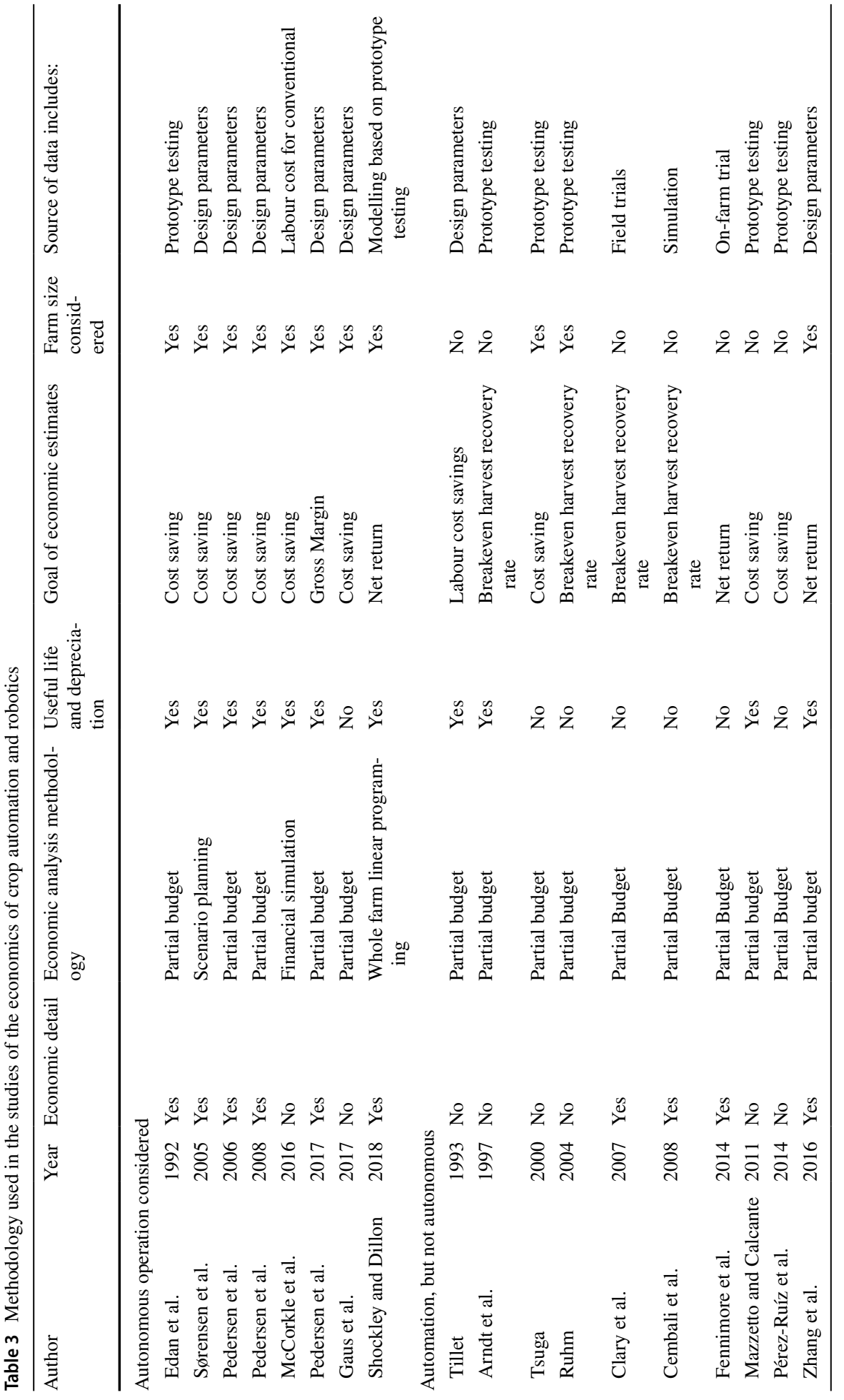


estimated useful life, salvage value, and effective field rate. As such, it is an example of a well-documented budget study.

In Denmark, Pedersen and colleagues used partial budgets to estimate the economic benefits of robots for crop scouting, mechanical weeding, grass cutting and spot reseeding. Pedersen et al. (2006) considered three scenarios. Key results included:

- Robotic crop scouting-They estimated an initial investment of $€ 7799$ for the robot scout and, for $500 \mathrm{ha}$, annual costs of $€ 15.60 / \mathrm{ha} / \mathrm{yr}$. They indicated that manual scouting with the same intensity would cost about $€ 19.40 / \mathrm{ha} / \mathrm{yr}$ for a cost savings of $€ 3.80$. Pedersen et al. (2006) did not estimate the pesticide cost saving with site-specific weed control, but noted that research indicated herbicide cost savings from 30 to $75 \%$.

- Robotic weeding-For horticultural crops, they estimated an initial cost of $€ 64,939$ for a weeding robot and, for a total area of $80 \mathrm{ha}$, an annual cost of $€ 260.40 / \mathrm{ha} / \mathrm{yr}$. Their robotic weeder was a micro-spray system. They estimated the cost of conventional weed control with broadcast herbicides and manual inter-row hoeing at $€ 296.6 / \mathrm{ha} / \mathrm{yr}$, resulting in a cost saving of $€ 36.20 / \mathrm{ha} / \mathrm{yr}$ for the robotic system.

- Robotic grass cutting-They estimated an initial cost of $€ 43,069$ for a golf course grass cutter. With a total area of $36 \mathrm{ha}$, it had an annual cost of $€ 283 / \mathrm{ha} / \mathrm{yr}$. Manual grass cutting was estimated to cost $€ 586.30 / \mathrm{ha} / \mathrm{yr}$, for a savings of $€ 303.30 / \mathrm{ha} / \mathrm{yr}$.

In each of the three scenarios, Pedersen et al. (2006) found cost savings with the robotic alternative, but stated that the high cost of real time kinematic global navigation satellite systems (RTK GNSS) and the modest capacity of the robots were the main reasons for the relatively high cost of the robotic systems.

The benefits of robotic weed scouting and robotic weeding were re-estimated by Pedersen et al. (2008). This analysis extended the Pedersen et al. (2006) study by estimating robotic weeding costs for USA, Greece and the UK, as well as for Denmark. They noted that the robotic weeder had an important cost advantage in the USA, UK and Denmark, but not in Greece. They found that differences in labour costs, crop rotation and farm structure may have important impacts on the potential use of these systems in different countries. Pedersen et al. (2008) emphasized the radical change in economies of scale when human operators are removed from farm equipment and the implications for farm size and structure. They also noted that country-to-country differences in safety regulations and insurance may have major cost implications.

The profitability of robots for early seeding and reseeding of sugar beets was estimated by Pedersen et al. (2017). Early seeding is a possibility with small robotic equipment because it is relatively light weight and could be in the field when it is too wet for conventional machinery. The study assumed that a robotic seeder could plant about 4 weeks earlier than conventional equipment. Based on planting time studies, they estimated a $2.67 \%$ yield increase from earlier planting. Assuming that the robotic seeder is used on 500 ha, they found that early seeding with the robot increased gross margin by about $€ 95$ or about $7.7 \%$. Of that increase, $€ 75 /$ ha was due to the yield increase and the remainder was cost savings mainly from reducing labour.

The early seeding and reseeding of sugar beets analysed by Pedersen et al. (2017) is an example of farming operations which are not feasible with conventional equipment, but would be possible with autonomous machines. Spot reseeding sugar beet maybe useful because of poor germination or because newly emerged plants are destroyed by flooding, rodents or other problems. Reseeding is often impossible with conventional equipment because machine operations would cause too much damage to the growing crop. A small 
robot would be able to do the reseeding while minimizing crushing or otherwise injuring the rest of the crop. Pedersen et al. (2017) assumed that spot reseeding increased overall yield by $5 \%$. Under that assumption, the gross margin increased about $€ 81 / \mathrm{ha}$, or about $6.5 \%$.

Gaus et al. (2017) used partial budgeting to estimate the potential cost of mechanically weeding wheat with a swarm of autonomous small robots. For a robot that could mechanically weed 3 ha of wheat five times in a crop season, they estimated an operating cost of $€ 30.20 / \mathrm{ha} / \mathrm{hr}$. They estimated the initial investment for one robot at $€ 626$. They commented on the potential pesticide cost savings by using robots for mechanical weeding, but did not quantify it by comparing the estimated cost of robotic weeding to typical chemical weeding expenses. They also commented on the potential for small robots to work in wet field conditions when conventional equipment would not be in the field and point out that working day data for small robots would be required to investigate the implications of this aspect of small robot use.

Among the documents reviewed, Shockley and Dillon (2018) took the most systematic view of how robotics might affect the economics of crop production. They considered autonomous equipment for maize and soybean production in Kentucky, USA, using a whole farm linear programming model. They assumed that all in-house field operations are potentially autonomous. They modelled planting, nitrogen fertilizer application and pesticide spraying as potentially autonomous, but that spreading phosphorous and potassium fertilizer, lime application and harvest were assumed to be done by (human) contractors. Parameters for autonomous equipment was based on prototypes developed and tested by their colleagues in the Department of Biosystems and Agricultural Engineering at the University of Kentucky. The analysis compared net returns from using autonomous equipment to the best complement of conventional equipment for a given farm size. The conventional tractor options ranged from 105 to $400 \mathrm{hp}$. The conventional sprayer alternatives in the model ranged from 8.2 to $36.6 \mathrm{~m}$. The analysis suggested that relatively small autonomous equipment would have economic advantages for a wide range of farm sizes, but especially for small farms.

Shockley and Dillon (2018) reported their key results in terms of the breakeven price of intelligent controls that would convert conventional tractors to autonomous. They considered four scenarios: (1) all costs and returns same as conventional production, (2) a 10\% reduction in input cost, mainly driven by site-specific pesticide application by the robot, (3) same as scenario 1, but with a $7 \%$ yield increase because of a reduction in soil compaction and (4) both the $10 \%$ input cost reduction and the $7 \%$ yield increase. The breakeven price of intelligent controls on an 850 ha farm were estimated by scenario as: (1) US $\$ 33,327$, (2) US $\$ 109,755$, (3) US\$243,436, and (4) US\$319,864. For some smaller farms in the range of 660-690 ha, the breakeven values for intelligent controls were higher i.e. (1) US\$61,017, (2) US $\$ 184,313$, (3) US $\$ 378,088$ and (4) US $\$ 494,194$. They argued that farm size must be factored into the market size assessment by equipment developers and manufacturers of robotic farm equipment.

\section{Automated, but not autonomous}

Of the 18 studies, ten focused on automating one or more horticultural production operations while retaining the human equipment operator (Tables 2, 3). All of the automation studies used partial budgeting methods that only accounted for the items that 
changed with the introduction of the technology, assuming that the overall production system remained the same.

Tillett (1993) explored the potential for use of a robotic arm in horticultural operations, especially harvest. He quantified potential costs, estimated labour savings and identified the length of the harvest season as a key variable in profitability. He concluded that a robotic harvester could be economically feasible for crops with a long harvest season, such as controlled environment tomatoes.

Arndt et al. (1997) and Clary et al. (2007) concentrated on identifying the percentage of potentially harvestable asparagus spears that must be harvested with automation to breakeven with manual harvest. Arndt et al. (1997) showed that even with grade No. 1 asparagus harvest at $28 \%$ and grade No. 2 at $15 \%$, the harvester provided a return over harvest costs. Clary et al. (2007) found that harvester would be economically successful if the harvest percentage were $70-80 \%$ of hand harvest. Cembali et al. (2008) focused on changes in the harvest interval with automation. They found that if the manual harvest cost increased from US $\$ 0.51$ to US $\$ 0.60 / \mathrm{kg}$, the automated harvest breakeven harvest rate dropped from 70 to $61 \%$. Ruhm (2004) stated that automated asparagus harvest could play an important role in decreasing production cost, but only with a substantial capital investment. He noted a capital cost for automated harvesters on a 50 ha asparagus operation of $€ 100,000$. Ruhm (2004) also indicated that fully automated asparagus grading would be economically viable if it had a capacity of $1600 \mathrm{spears} / \mathrm{h}$.

Three studies estimated the cost savings from automation for automated transplanting and weed control (i.e. Tsuga 2000; Mazzetto and Calcante 2011; and Pérez-Ruíz et al. 2014). Tsuga (2000) estimated a cost curve for an automated vegetable transplant machine and found that the machine competed with manual labour if the area covered was over 8.21 ha. Pérez-Ruíz et al. (2014) showed that the co-robotic weeding of broccoli reduced labour time by $13.8 \mathrm{~h} / \mathrm{ha}$, and cut weeding labour cost by US\$170.15/ha. The term "co-robotic" is used when robots work co-operatively with human workers. The cost of the weeding robot was not estimated, and consequently the economic viability was not determined. Mazzetto and Calcante (2011) showed that an automated grape vine transplanter increased the work rate by about $15 \%$, mainly by eliminating a worker responsible for physically laying out the vineyard. The automated transplanter followed a virtual design. An estimated cost curve showed that the automated vine transplanter was the lower cost option if the area transplanted annually exceeded about 23 ha.

Zhang et al. (2016) considered a self-propelled apple harvesting and in-field sorting machine. They estimated that the equipment would save the average New York apple orchard US\$149,438 and reduce net returns to the average California orchard by US $\$ 3,381$. The difference in benefits depended on orchard area, production level and the percentage of processing apples.

All ten of the automation studies identified scenarios in which automation was economically beneficial. Of the ten studies, Fennimore et al. (2014) were most sceptical about the benefits. They stated that with the technology available at that time, machine vision-guided weeding with a rotating cultivator between plants was economically feasible for transplanted vegetables, but not for the direct seeded crops on which field trials had been conducted. The machine vision-guided weeding reduced the stand of seeded lettuce by $22-28 \%$, but the stand of transplanted lettuce was reduced by only $6-9 \%$ compared to the standard cultivator. Combining the rotating cultivator with herbicide treatment reduced the number of weeds intra-row and consequently the damage to the crop. For transplanted celery, combining the rotating cultivator with herbicide resulted in an 
average gain over two trials of US\$815/ha, while the zero-herbicide rotating cultivator resulted in a loss of US\$4857.50/ha.

\section{General comments}

All of the robotic economics studies focused on relatively small robots. For example, the autonomous tractor in the Shockley and Dillon (2018) study was $46 \mathrm{hp}$ and the sprayer was $6.1 \mathrm{~m}$ wide. None of the studies reviewed have opted to assess the economics of autonomous versions of the large scale equipment used on most commercial farms today. It should be noted that the major farm equipment companies have released information about their research and development programs focused on autonomous large scale equipment (e.g. CNH 2016; Daniels 2016).

Farm size was considered in all of the eight studies of economics with autonomous equipment (Table 3), but not in most of the automation economics studies. For the automation studies, it was plausible to assume that increasing the number of automated machines according to farm size would lead to an equivalent increase in cost and output, hence creating a situation of constant returns to scale. The main complications are the discrete steps introduced by fixed equipment sizes (e.g. 1-row, 2-row or 3-row). Among the studies of economics with autonomous equipment, Edan et al. (1992) estimated the area of melon production needed for breakeven given alternative manual labour wage rates. Sørensen et al. (2005) and Gaus et al. (2017) estimated cost of autonomous weeding given fixed crop area and farm sizes. The studies by Pedersen and colleagues (Pedersen et al. 2006; 2008; 2017) estimated costs of autonomous equipment for a given area. McCorkle et al. (2016) estimated how replacing manual labour with robots would affect vineyards of different sizes. Shockley and Dillon (2018) considered farm sizes ranging from 40 to 1240 ha.

Most of the 18 studies with economic analysis used the technical design parameters or data collected in prototype testing. One exception is Cembali et al. (2008) who used crop simulation to estimate asparagus growth and timing, but based harvest equipment parameters on design parameters and prototype testing information. The other exception is Fennimore et al. (2014) who used on-farm trial data. All of the economic studies show signs of being data-constrained. For example, Shockley and Dillon (2018) stated: "Economic modelling of autonomous machinery is scarce because of the lack of necessary data" (p. 7). Most of the studies probably chose to use partial budgets, targeting cost saving or breakeven harvest recovery rates because that was the least data-demanding approach. On-farm experience with autonomous field crop equipment is rare because it has just started being commercialized and for the most part still existed mostly in the form of prototypes. The lack of data is complicated by the fact that while much of the basic science for development of ag robotics is done in the public sector, the development of practical autonomous tools is a business opportunity. Businesses usually want to control the information being made public about any new products or services, consequently they are not eager to share robot work rates, reliability, maintenance and repair costs, and other operational detail that is essential for economic assessment.

Only one of the 18 studies which include economic analysis was originally presented or published for an audience of economists (i.e. Gaus et al. 2017). All of the other studies were presented or published to audiences dominated by engineers or horticulturists (Table 2), but the majority included economists as co-authors. This is consistent with the observation that disciplinary economics is mostly focused on the development of new research tools. The assessment of the economics of agricultural automation/robotics uses 
well established economic methods, consequently the audience is among engineers and agricultural scientists who are interested in the economic implications of their innovation.

\section{Discussion}

The publicly available research on the economics of crop automation and robotics is minimal compared to the need. Gaps identified include:

- Systems analysis-The partial budgeting used by most of the studies is a useful starting point, but cannot shed light on some of the key hypotheses about the economic impact of crop robotics. For example, the economies of scale in agriculture are radically changed when human operators are removed and the equipment is made autonomous (Pedersen et al. 2008). With autonomous equipment, the motivation for large equipment is much diminished and optimal farm size is probably affected. Various research methodologies have been used to investigate economies of scale and optimal farm size in agriculture, but given the lack of on-farm experience with autonomous equipment, the initial studies are likely to use whole farm mathematical programming models.

- Farm surveys and on-farm trials-Very few of the economic studies of crop automation/ robotics incorporated farm experience because use of these machines on farms is very new. Some farmer robotic agriculture testimonials are available on the internet (e.g. Future Farming 2018; Naïo Technologies 2017; Progressive Farmer 2018), but quantification of key parameters is lacking. As autonomous farm equipment and mechatronic automated machines become commercially available, on-farm trials become possible. Classic on-farm trial protocols could be adapted or some of the new on-farm trial designs that make use of electronic data collection (e.g. Bullock et al. 2009) could be used. To be credible, the trials probably need to be led by a non-commercial entity (e.g. university, research institute, NGO). To have access to the latest technology, they probably need to be implemented in collaboration with the equipment manufacturers and retailers. Farmers need to be identified who are curious enough to commit their land, labour and management. While some in-kind contributions of equipment, land, labour, scientific expertise are likely from research institutions or businesses, government or philanthropic funding will probably be needed to prime the pump.

- Robot size-All of the publicly available research studies of the economics of agricultural robotics focus on relatively small robots, but the major farm equipment companies are focusing on autonomous versions of their largest equipment (CNH 2016; Daniels 2016). Evidence is needed on the optimal robot size for a given farm type and set of tasks. This analysis would need to include many factors including: robot cost, maintenance expense, work rates under different farm conditions, energy consumption, compaction and resulting yield effects, legal and regulatory restrictions and transport between fields and farmstead to field.

- Changing structure of the farm equipment market - In much of the world, farmers traditionally owned most farm equipment. In the conventional farm equipment market, there is talk of moving to a "licence to operate" structure which gives the farmer the right to use equipment, but limits the right to repair or modify. That license to operate approach is in part driven by the intellectual property that companies have in the software required to operate new farm equipment (e.g. Solon 2017; Wiens and Chamberlain 2018). Among robotics entrepreneurs, there is talk of a service model, perhaps 
like the model used by the transportation company Uber. Under that model, a farmer who needs a field weeded would book that service on the internet and the closest robots would come and weed. For farmers, this is attractive, especially at the beginning of robotic agriculture transitions, because it reduces the need to invest in technology that may become rapidly obsolete. On the entrepreneurial side, the service model allows the company to capture more of the learning that comes with operating robots in the field. A robotic service model has implications for the size and organization of farms.

- Market size estimates-Almost all of the studies were able to find some scenarios in which automated field operations with a human equipment operator or autonomous field operations were profitable, but that does not mean special purpose autonomous equipment/robots will be developed for all those situations. In many cases (especially for horticulture), the size of the market for a given machine or robot may be too small to cover the development cost. Equipment companies and agricultural consulting firms have done proprietary market assessments that are available only to paying customers and which may have gaps. Research-based market assessments would serve entrepreneurs, smaller companies and the public sector. Public funding organizations need to understand market size before committing research money to automation or robotics. For example, the public good generated by supporting research to automate a handful of fruit or vegetable producers may not justify the investment. With market size estimates, engineers, entrepreneurs, venture capitalists and public funding agencies could decide where on the continuum between a general purpose robot and a highly specialized machine, would maximize benefits.

- Studies on grain, oilseeds, cotton and other commodity crops-Most of the automation/ robotics economics studies focused on horticultural crops. Sørensen et al. (2005), Pedersen et al. (2006), (2008) and Pedersen et al. (2017) focused on sugar beet. Sørensen et al. (2005), Pedersen et al. (2006), Gaus et al. (2017) and Shockley and Dillon (2018) estimated some benefits for cereals. The focus on automation/robotics for horticulture is logical because it is often a high value crop. In terms of potential equipment market size and food security implications, the commodity crops cannot be ignored. Like the Sørensen et al. (2005), Pedersen et al. (2006), and Shockley and Dillon (2018) studies, initial economic analysis will make use of design parameters, data collected in prototype tests and imagination. To understand the market and public good implications, it is key to start exploring the potential of automation and robots for commodity crops.

- Co-robotics or "Cobots"-The entirely autonomous farm is probably several decades in the future. In the meantime, farmers and agribusinesses will need to learn to work with automation and autonomous machines. The concept of humans working with robots is often call "Co-robotics" or "Cobots". A combination of modelling studies and on-farm trials can start to identify the sweet spots for human-robot interaction in agriculture.

- National, regional and sector level economic impacts and externalities have been hypothesized for field crop robots (Lowenberg-DeBoer 2018), but none of the publicly available studies have examined those potential impacts. For example, small robots could almost eliminate the competitive advantage that large rectangular fields have in commodity agriculture. With robots, small, irregularly shaped fields in areas with good soils, reliable rainfall and market access (e.g. Western Europe, Eastern USA) may be much more competitive in grain and oil seed production in the future. Other examples involve the impact of robots on the labor market. Widespread use of robots could almost eliminate the need for unskilled labor in agriculture in industrialized countries thereby wiping out a category of entry level jobs. Robots could also change immigration flows if the demand drops for unskilled workers in crop production (especially hor- 
ticultural crop production). The change in field crop labour requirements would affect the political debate around immigration in industrialized countries, unemployment levels in the developing countries that are now supplying unskilled agricultural migrants and remittance flows back to those countries. At least one model of this type of study exists for the greenhouse sector (Posadas 2012). He collected data in the South-Eastern USA on the economic impact of mechanization and automation in greenhouse and nursery companies. He concluded that mechanization and automation increased the gross revenue of horticultural production businesses, and allowed them to pay higher wages and retain workers longer. They also hired fewer new skilled workers. Studies of the national, regional and sector level economic impact of field crop robots have the potential to guide policy and influence business/farm level technology planning.

- The cost effectiveness of achieving environmental benefits using crop roboticsA wide range of environmental benefits are hypothesized to result from crop robotics (Sørensen et al. 2005; Duckett et al. 2018; Lowenberg-DeBoer 2018; Finger et al. 2019), but none have been quantitatively documented. Those environmental benefits include reduced pesticide use, less soil compaction and the ability to farm around trees, rocks, streams and other features of the natural landscape. Crop robotics may or may not be a cost-effective way of achieving environmental goals compared to other management methods.

- The cost/benefit of robotic safety regulations-For example, some European Union countries require a human supervisor to be physically present in the field where a crop robot is working. Such a regulation would substantially reduce the economic benefit of crop robotics; if a human must be physically present, he or she may just as well be operating the equipment. If the goal is human safety, would better sensors to detect humans in the field or fencing to reduce human-robot encounters be a more cost-effective solution?

- Value of agricultural data collected by automation/robots-Among the studies reviewed, robots for crop scouting and data gathering are represented (Pedersen et al. 2006; 2008), but the value of the data that crop robots could collect as they go about other tasks is not explicitly considered. It is possible that the detailed data collected could turn out to be at least as valuable as the labour savings. For instance, a weeding robot in a broccoli field might also collect data on the formation of broccoli heads which would form the basis for a selective harvest strategy and a marketing plan.

- Robotics and automation in the developing world-Commentators have pointed out the potential for robotics and automation in developing world agriculture (e.g. Tarannum et al. 2015; Schlogl and Sumner 2018; Kushwaha et al. 2016), but research is scarce. Farm labour is increasingly hard to find everywhere in the world, including developing countries. In the developing world, young people go to the cities making it difficult to maintain labour intensive traditional production systems. The conventional wisdom is that developing world agriculture needs motorized mechanization, but that technology is most efficient when it can be operated in the context of large rectangular fields. Creating large rectangular fields in a landscape previous dominated by small farm agriculture is very socially, economically and environmentally disruptive. It would mean cutting down field trees and bushes, changing watercourses, and in some cases moving villages. Robotics might offer a way for developing country agriculture to skip the motorized mechanization step. If a developing country farmer would buy a simple robot that could plant, weed and harvest for the price of a motor bike, he or she might be able to bring the latest in agricultural technology to the farm without drastically altering the small farm landscape. This kind of research would probably require collaboration 
with advanced engineering, agriculture and economic research institutions from the industrialized world with the international agricultural research centres of the Consultative Group for International Agricultural Research (CGIAR) and national agricultural research systems (NARS). The CGIAR and the NARS have only just started to think about the potential for robotics in their environment.

\section{Conclusions}

This study showed that while research on crop robotics is relatively abundant, studies on the economics of that technology are scarce. The review identified only 18 studies since 1990 which estimated the profitability or cost-effectiveness of crop robotics. Of those 18 studies, eight consider autonomous equipment and ten focus on automated equipment with human operators. Seventeen of the eighteen studies use budgeting to estimate the cost effectiveness of robotics for specific crop operations. Only one study used farm level linear programming to examine the systemic impacts of crop robotics. All the studies focused on private monetary benefits of crop robotics; none of them estimated the economic impacts beyond the farm gate or the potential environmental and social impacts. The results of this review reinforce the need for economic research on crop robotics. Research needs include:

- Impacts on different crops-Most existing crop robotics studies focus on horticultural or industrial crops, but grains and oilseeds may be the "low handing fruit" for robotics entrepreneurs because most grain and oilseed production is already mechanized. Robotics would only need to make that equipment autonomous.

- System analysis-Switching from conventional mechanization to crop robots may have systemic effects that ripple through the whole farm.

- Farm level robotics testing-Farmer experience with new technologies is often different from the use intended by researchers and manufacturers.

- Robot size-With conventional mechanization, the economic rule of thumb is "bigger is better". That may change when human operators are no longer needed.

- Structure of farm equipment market-Traditionally, farmers have owned most farm equipment. With robotics leasing or a service provide model may have advantages for both farmers and equipment providers.

- Market size estimates-The types of crop robots commercialized will depend in part on market size. Highly specialized robots would be commercialized only for relatively large markets and/or high value crops. A general purpose robot with specialized attachments would probably be best for a mosaic of niche markets.

- Co-robotics or cobots-What is the optimal combination of human operated equipment and autonomous equipment for a given farm? While robotic technology is being developed, it is almost inevitable that humans and robots will work together.

- National, regional and sector level impacts and externalities-Crop robotics will impact labour markets, farm structure and agricultural policy.

- Cost-effectiveness of using robotics to achieve environmental and social goals-crop robotics are a potentially win-win strategy that uses profitable technology with environmental and social benefits.

- Cost/benefit of robotic safety regulations - initial crop robot safety regulations in some countries focus on human supervision. Fencing to limit human-robot interaction, and better sensors and software to detect humans, might be more cost effective. 
- Value of data collected by robotic operations-Some researchers have argued that the value of data collected by crop robots may exceed the labour savings.

- Potential for crop robotics in the developing world-The shortage of farm labour and the need to manage agricultural inputs more precisely is worldwide, but automation technology may differ by farm structure and local needs.

\section{Compliance with ethical standards}

Conflict of interest The authors declare that they have no conflict of interest.

Open Access This article is distributed under the terms of the Creative Commons Attribution 4.0 International License (http://creativecommons.org/licenses/by/4.0/), which permits unrestricted use, distribution, and reproduction in any medium, provided you give appropriate credit to the original author(s) and the source, provide a link to the Creative Commons license, and indicate if changes were made.

\section{References}

Arndt, G., Rudziejewski, R., \& Stewart, V. A. (1997). On the future of automated selective asparagus harvesting technology. Computers and Electronics In Agriculture, 16(2), 137-145. https://doi. org/10.1016/S0168-1699(96)00033-6.

Blackmore, B. S. (2007). A systems view of agricultural robots. In J. V. Stafford (Ed.), Precision Agriculture '07 (pp. 23-31). Wageningen: Wageningen Academic Publishers.

Borenstein, M., Hedges, L. V., Higgins, J. P. T., \& Rothstein, H. R. (2009). Introduction to Meta-Analysis. Chichester: Wiley.

Bullock, D. S., Ruffo, M. L., Bullock, D. G., \& Bollero, G. A. (2009). The value of variable rate technology: an information-theoretic approach. American Journal of Agricultural Economics, 91(1), 209-223. https://doi.org/10.1111/j.1467-8276.2008.01157.x.

Cembali, T., Folwell, R. J., Clary, C., \& Mari, M. (2008). Economic comparison of selective and nonselective mechanical harvesting of asparagus. International Journal of Vegetable Science, 14(1), 4-22. https ://doi.org/10.1080/19315260801890476.

Clary, C., Ball, T., Ward, E., Fuchs, S., Durfey, J., Cavalieri, R., et al. (2007). Performance and economic analysis of a selective asparagus harvester. Applied Engineering in Agriculture, 23(5), 571-577. https ://doi.org/10.13031/2013.23665.

CNH Industrial. (2016). CNH Industrial Brands Reveal Concept Autonomous Tractor Development. Retrieved September 2, 2018 from http://www.cnhindustrial.com/en-us/media/press_releases/2016/ august/Pages/CNH_Industrial_brands_reveal_concept_autonomous_tractor_development_Annou ncement.aspx

Dairy Global. (2015). Milking automation is gaining popularity, 15 January 2015. Retrieved September 2, 2018, from https://www.dairyglobal.net/Milking/Articles/2015/1/Milking-automation-is-gaining-popul arity-1568767W/.

Daniels, J. (2016). Future of farming: driverless tractors, ag robots, CNBC, 16 Sept. 2016. Retrieved September 2, 2018, from https://www.cnbc.com/2016/09/16/future-of-farming-driverless-tractors-ag-robot s.html.

Duckett, T., Pearson, S., Blackmore, S., \& Grieve, B. (2018). Agricultural robotics: the future of robotic agriculture. UK-RAS White Papers, EPSRC UK-Robotics and Autonomous Systems Network. Retrieved September 2, 2018, from https://arxiv.org/ftp/arxiv/papers/1806/1806.06762.pdf.

Edan, Y., Benady, M., \& Miles, G. E. (1992). Economic analysis of robotic melon harvesting. Paper no. 92-1512, St Joseph, MI, USA: ASAE.

Fennimore, S. A., Smith, R. F., Tourte, L., LeStrange, M., \& Rachuy, J. S. (2014). Evaluation and economics of a rotating cultivator in bok choy, celery, lettuce, and radicchio. Weed Technology, 28(1), 176-188. https://doi.org/10.1614/WT-D-13-00051.1. 
Finger, R., Swinton, S., El Benni, N., and Walter, A. (2019). Precision farming at the nexus of agricultural production and the environment. Annual Review of Resource Economics. Forthcoming.

Future Farming. (2018). Farmer shares his experiences using a robotic tractor, 23 March, 2018. Retrieved September 2, 2018, from https://www.futurefarming.com/Machinery/Articles/2017/6/Farmer-share s-his-experiences-using-a-robotic-tractor-1614WP/.

Gaus, C. C., Urso, L.M., Minßen, T. F., \& de Witte, T. (2017). Economics of mechanical weeding by a swarm of small field robots. 57th Annual Conference (pp. 1-4), Brunswick, Germany: German Association of Agricultural Economists (GEWISOLA).

Kushwaha, H., Sinha, J., Khura, T., Kushwaha, D. K., Ekka, U., Purushottam, M., et al. (2016). Status and scope of robotics in agriculture. Kharagpur, India: International Conference on Emerging Technologies in Agriculture and Food Engineering, pp. 264-277.

Lowenberg-DeBoer, J. (2018). The economics of precision agriculture. In J. V. Stafford (Ed.) Precision Agriculture for Sustainability, Cambridge, UK: Burleigh Dodds Science Publishing Ltd, http:// dx.doi.org/10.19103/AS.2017.0032.19.

Mazzetto, F., \& Calcante, A. (2011). Highly automated vine cutting transplanter based on DGNSS-RTK technology integrated with hydraulic devices. Computers and Electronics in Agriculture, 79(1), 20-29. https://doi.org/10.1016/j.compag.2011.08.007.

McCorkle, D. A., Dudensing, R. M., Hanselka, D., \& Hellman, E. W. (2016). Economics of robotic technology in texas wine grape production. San Antonio, USA: Southern Agricultural Economics Association. 2016 SAEA Annual Meeting, 1-22.

Moher D, Liberati A, Tetzlaff J, Altman DG, PRISMA Group. (2009). Preferred reporting items for systematic reviews and meta-analyses: The PRISMA Statement. British Medical Journal, 339, b2535. https://doi.org/10.1136/bmj.b2535.

Naïo Technologies. (2017). The Oz weeding robot on a produce farm-Testimonial, 14 June 2017. Retrieved September 2, 2018, from https://www.naio-technologies.com/en/oz-robot-produce-farm/.

Pedersen, S. M., Fountas, S., \& Blackmore, S. (2008). Agricultural robots-applications and economic perspectives. In Y. Takahashi (Ed.), Service Robot Applications (pp. 369-382). Rijeka: InTech.

Pedersen, S. M., Fountas, S., Have, H., \& Blackmore, B. S. (2006). Agricultural robots-system analysis and economic feasibility. Precision Agriculture, 7(4), 295-308. https://doi.org/10.1007/s1111 9-006-9014-9.

Pedersen, S. M., Fountas, S., Sørensen, C. G., Van Evert, F. K., \& Blackmore, B. S. (2017). Robotic seeding: economic perspectives. In S. M. Pedersen \& K. M. Lind (Eds.), Precision Agriculture: Technology and Economic Perspectives (pp. 167-179). Cham: Springer International Publishing. https://doi.org/10.1007/978-3-319-68715-5_8.

Pérez-Ruíz, M., Slaughter, D. C., Fathallah, F. A., Gliever, C. J., \& Miller, B. J. (2014). Co-robotic intra-row weed control system. Biosystems Engineering, 126, 45-55. https://doi.org/10.1016/j.biosy stemseng.2014.07.009.

Posadas, B. (2012). Economic impacts of mechanization or automation on horticulture production firms sales, employment, and workers' earnings, safety, and retention. HortTechnology, 22(3), 388-401.

Progressive Farmer. (2018). Automated farming: remote-controlled machinery reduces cost, 30 January, 2018. Retrived April 25, 2018, from https:/www.dtnpf.com/agriculture/web/ag/news/crops/artic le/2018/01/30/remote-controlled-machinery-reduces-3.

Robot Institute of America (RIA) (undated). Introduction to Robotics. Retrived September 2, 2018, from http://www.bowlesphysics.com/images/Robotics_-_A_historical_perspective.pdf.

Ruhm, G. (2004). Economic evaluation of various harvesting, grading and cultivation methods for asparagus. Acta Horticulturae, 655, 503-507. https://doi.org/10.17660/ActaHortic.2004.655.61.

Schlogl, L., \& Sumner, A. (2018). The rise of the robot reserve army: automation and the future of economic development, work, and wages in developing countries. London School of Economics, Working Paper 487, July 2018. Retrived September 2, 2018, from https://www.cgdev.org/publicatio n/rise-robot-reserve-army-automation-and-future-economic-development-work-and-wages.

Shamshiri, R. R., Weltzien, C., Hameed, I. A., Yule, I. J., Grift, T. E., Balasundram, S. K., et al. (2018). Research and development in agricultural robotics: A perspective of digital farming. International Journal of Agricultural Biological Engineering, 11(4), 1-14. https://doi.org/10.25165/j.ijabe.20181 104.4278.

Shockley, J. M., \& Dillon, D. (2018). An economic feasibility assessment for adoption of autonomous field machinery in row crop production. Montreal, Canada: the 14th International Conference on Precision Agriculture. Retreived October 30, 2018, from https://www.ispag.org/proceedings/?actio $\mathrm{n}=$ download\&item $=4749$.

Simon, M. (2017). What is a robot? Wired. Retreived September 2, 2018, from https://www.wired.com/ story/what-is-a-robot/. 
Solon, O. (2017). A right to repair: why Nebraska farmers are taking on John Deere and Apple, The Guardian, 6 March 2017. Retreived September 2, 2018, from https://www.theguardian.com/envir onment/2017/mar/06/nebraska-farmers-right-to-repair-john-deere-apple.

Sørensen, C. G., Madsen, N. A., \& Jacobsen, B. H. (2005). Organic farming scenarios: operational analysis and costs of implementing innovative technologies. Biosystems Engineering, 91(2), 127-137. https:// doi.org/10.1016/j.biosystemseng.2005.03.006.

Tarannum, N., Rhaman, M. K., Khan, S. A., \& Shakil, S. R. (2015). A brief overview and systematic approach for using agricultural robot in developing countries. Journal of Modern Science and Technology, 3, 88-101.

Thomas, J., Brunton, J., and Graziosi, S. (2010). EPPI-Reviewer 4.0: software for research synthesis. EPPICentre Software. London, UK: Social Science Research Unit, Institute of Education, University of London.

Tillett, N. D. (1993). Robotic manipulators in horticulture: A review. Journal of Agricultural Engineering Research, 55(2), 89-105. https://doi.org/10.1006/jaer.1993.1035.

Tsuga, K. (2000). Development of fully automatic vegetable transplanter. JARQ, Japan Agricultural Research Quarterly, 34(1), 21-28.

Wiens, K., and Chamberlain, E. (2018). John Deere just swindled farmers out of their right to repair, WIRED, 19 September 2018. Retreived October 20, 2018, from https://www.wired.com/story/johndeere-farmers-right-to-repair/.

Zhang, Z., Pothula, A. K., \& Lu, R. (2016). Economic analysis of a self-propelled apple harvest and in-field sorting machine for the apple industry. Paper number: 162456644, St Joseph, MI, USA: ASABE. https ://doi.org/10.13031/aim.20162456644.

Publisher's Note Springer Nature remains neutral with regard to jurisdictional claims in published maps and institutional affiliations. 